
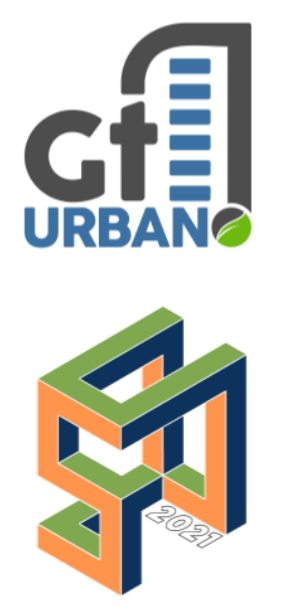

SINGEURB

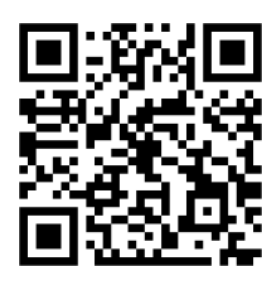

Como citar:

PROCÓPIO, Carmem M. O; PINA, Silvia A. M. G. Morfologias urbanas humanizadas do espaço livre em áreas habitacionais sociais. In: III

SIMPÓSIO

NACIONAL DE GESTÃO E ENGENHARIA URBANA: SINGEURB, 2021, Maceió. Anais... Porto Alegre: ANTAC, 2021. p. 308-321. Disponível em: https://eventos.antac. org.br/index.php/sing eurb/issue/view/14

\section{Morfologias urbanas humanizadoras do espaço livre em áreas habitacionais sociais} Humanizing urban morphologies of open space
in social housing areas

Carmem M. O. Prócopio, Universidade Estadual de Campinas

(UNICAMP), carmem.procopio@gmail.com

Silvia A. M. G. Pina, Universidade Estadual de Campinas (UNICAMP), smikami@unicamp.br

\section{RESUMO}

Além da desigualdade econômica e da falta de política habitacional efetiva, a concepção dos projetos habitacionais sociais é um dos fatores para a baixa qualificação dos espaços coletivos e públicos, pois muitas vezes o projeto desconsidera a integração com o espaço urbano, as dinâmicas preexistentes e as demandas dos moradores, formulando áreas urbanas monofuncionais e espaços públicos pouco acolhedores. O objetivo deste artigo é apresentar os resultados obtidos em estudo desenvolvido no mestrado cuja finalidade foi identificar as espacialidades e apropriações dos espaços livres públicos e coletivos em conjuntos habitacionais sociais realizados na cidade de São Paulo, entre 2001 e 2016. O Heliópolis Gleba G e o Jardim Nazaré foram as unidades de caso selecionadas para estudo. A análise qualitativa considerou a seleção de variáveis morfológicas e humanizadoras para verificação da qualidade dos espaços livres públicos e coletivos. Os resultados apontam algumas tendências, pistas e indícios de qualidades espaciais que intensificam as apropriações e salientam a importância de valorizar morfologias urbanas capazes de estimular o dinamismo das práticas cotidianas, contribuindo para o debate de métodos e estudos de avaliação de sistemas de espaços livres.

Palavras-chave: Habitação Social; Morfologia urbana; Espaço Livre.

\begin{abstract}
Among other things like economic inequality and the lack of effective housing policy, the design of social housing is one of the factors for the low qualification of collective and public spaces, due to the fact the project often disregards the integration with urban space, preexisting dynamics and the demands of residents, develop monofunctional urban areas and inhospitable public spaces. The aim of this article is to present the final results achieved in a research developed in the master's course whose purpose was to identify the spatialities and appropriations of public and collective open spaces in social housing designs in the city of São Paulo, between 2001 and 2016. The Heliópolis Gleba Ge Jardim Nazaré were the case units selected for study. Qualitative analysis considered the selection of morphological and humanizing variables to verify the quality of public and collective open spaces. The results point to trends, clues and evidence of spatial qualities that intensify appropriations and highlight the importance of valuing urban morphologies capable of stimulating the dynamism of everyday practices, contributing to the debate on methods and studies for evaluating open space systems.
\end{abstract}

Keywords: Social Housing; Urban Morphology; Open Space. 


\section{INTRODUÇÃO}

A produção habitacional social nacional, realizada pelo BNH (1964 a 1986) e PMCMV (2009 a 2020), é marcada em sua maioria por edifícios dispostos de forma isolada nas parcelas, sem configurar pátios ou ruas agradáveis para os moradores. Esse modo de conceber cidade deixa escapar a potência dos espaços livres, principalmente os de uso coletivo, da convivência entre diferentes, para trocas comerciais, permanência e lazer, apoiando a construção do habitar (TELLES, 1990; SANTOS e VOGEL, 1985). Essa situação é mais alarmante nas áreas habitacionais sociais onde a experiência da escassez (SANTOS, 1996) é sentida fortemente pelos seus moradores que vivem em unidades habitacionais com dimensões reduzidas em bairros com infraestrutura insuficiente para a vida cotidiana (PELLI, 2007).

Sendo assim, olhar a construção integrada do edifício com o espaço público foi o que estimulou o desenvolvimento dessa pesquisa, ao identificar as espacialidades e apropriações dos espaços livres públicos e coletivos em áreas habitacionais sociais da cidade de São Paulo, que foram objeto de intervenção urbana entre 2001 e 2016, relacionando-as com as características morfológicas desses locais. Os resultados apontam tendências, pistas projetuais e indícios de qualidades espaciais que intensificam as apropriações e salientam a importância de valorizar morfologias urbanas capazes de estimular o dinamismo das práticas cotidianas.

\section{MÉTODO DE ANÁLISE}

Para realizar a análise, as variáveis encontradas em metodologias de avaliação e análise da qualidade do espaço público foram sistematizadas e organizadas em dois grupos: (i) da Dimensão Morfológica, incluindo variáveis que caracterizam a forma urbana das áreas selecionadas para análise e (ii) da Dimensão Humanizadora, contendo variáveis capazes de estimular as ações das pessoas, pois estão relacionadas com a percepção e com o comportamento humano nos espaços livres conformados ou não pelas edificações. Após essa sistematização, as apropriações identificadas foram relacionadas com os fatores qualitativos elencados no quadro 1 e as espacialidades identificadas foram classificadas em espacialidades públicas, sociais e privadas (QUEIROGA, 2006). 
Quadro 1 - Fatores qualitativos para análise dos espaços livres

\begin{tabular}{|c|c|c|c|}
\hline CATEGORAA & EEMENTOS & FATO RESQ UAUTATIVOS & $\begin{array}{l}\text { RËPÉNK IA } \\
\text { METODOLÓGICA }\end{array}$ \\
\hline \multirow{7}{*}{ 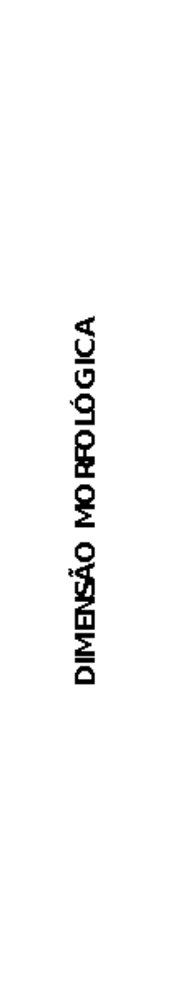 } & $\begin{array}{l}\text { RUA - } \\
\text { PARCEA - } \\
\text { EDIF́C O }\end{array}$ & $\begin{array}{l}\text { Tipologia edilíc ia (Continuidade e afastamento } \\
\text { com a rua; disposição do edifíc io no bte) }\end{array}$ & $\begin{array}{l}\text { García-Pérezetal } \\
(2020)\end{array}$ \\
\hline & PUA & Permeabilidade & $\begin{array}{l}\text { García-Pérezetal } \\
\text { (2020); Be ntleyetal } \\
\text { (1985); Brandão (2002) }\end{array}$ \\
\hline & \multirow{3}{*}{ PARCEA } & \multirow[b]{2}{*}{ Tipologia do espaço live re residenc ial } & $\begin{array}{l}\text { García-Pérezetal } \\
(2020) ; \\
\text { Barros (2008) }\end{array}$ \\
\hline & & & $\begin{array}{l}\text { García-Pérezetal } \\
(2020) ; \\
\text { Baros (2008) }\end{array}$ \\
\hline & & Prog resso e Hierarq uia & Bamos (2008) \\
\hline & \multirow{2}{*}{ EDIF́C 10} & Densidade c onstrutiva e habita c ional & $\begin{array}{l}\text { García-Pérez etal } \\
\text { (2020); Berg hauser } \\
\text { Ponte Haupt, (2009) }\end{array}$ \\
\hline & & Diversid ade ed ilíc ia & $\begin{array}{l}\text { García-Pérezetal } \\
(2020)\end{array}$ \\
\hline \multirow{6}{*}{ 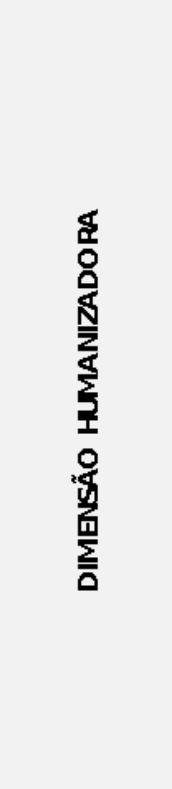 } & \multirow{4}{*}{$\begin{array}{l}\text { FOPMA } \\
\text { URBANA - SER } \\
\text { HUMANO }\end{array}$} & Desenho na altura dos olhos & $\begin{array}{l}\text { García-Pérezetal } \\
\text { (2020); Gehl (2015) }\end{array}$ \\
\hline & & Limite e Pemeabilidade da edific ação & Bamos (2008) \\
\hline & & Versa tilid ade & $\begin{array}{l}\text { Bentleyetal (1985); } \\
\text { Brandão (2002) }\end{array}$ \\
\hline & & Aprazibilidade & $\begin{array}{l}\text { Bentleyetal (1985); } \\
\text { Brandão (2002) }\end{array}$ \\
\hline & \multirow[t]{2}{*}{ SERHUMANO } & Segurança e Conservação & $\begin{array}{l}\text { Brandão (2002); } \\
\text { Gehl(2015) }\end{array}$ \\
\hline & & Identidade & $\begin{array}{l}\text { Bentleyetal (1985); } \\
\text { Brandäo (2002) }\end{array}$ \\
\hline
\end{tabular}

Fonte: As autoras (2021) 


\section{ESTUDOS DE CASO}

A seleção das unidades de estudo considerou estudo realizado sobre a produção habitacional de interesse social entre 2001 e 2016 (PROCOPIO e PINA, 2019), que demonstrou que 75\% são edificações isoladas no lote e $25 \%$ são de outro tipo de configuração morfológica. A partir desse menor universo, os conjuntos Heliópolis Gleba G e o Jardim Nazaré foram selecionados para o estudo de caso. Para cada unidade de caso foi realizado levantamento documental e iconográfico, acompanhado de visitas de campo para registrar e identificar as apropriações.

\subsection{Heliópolis Gleba G}

Localizado na região norte de Heliópolis, uma das maiores favelas da cidade de São Paulo, o setor estudado era um alojamento provisório antes da intervenção urbana. As edificações existentes foram demolidas e a quadra foi dividida em dois lotes para a construção de dois conjuntos habitacionais verticais. A pesquisa analisou o sistema de espaços livres do primeiro conjunto entregue em 2014 (figura 1).

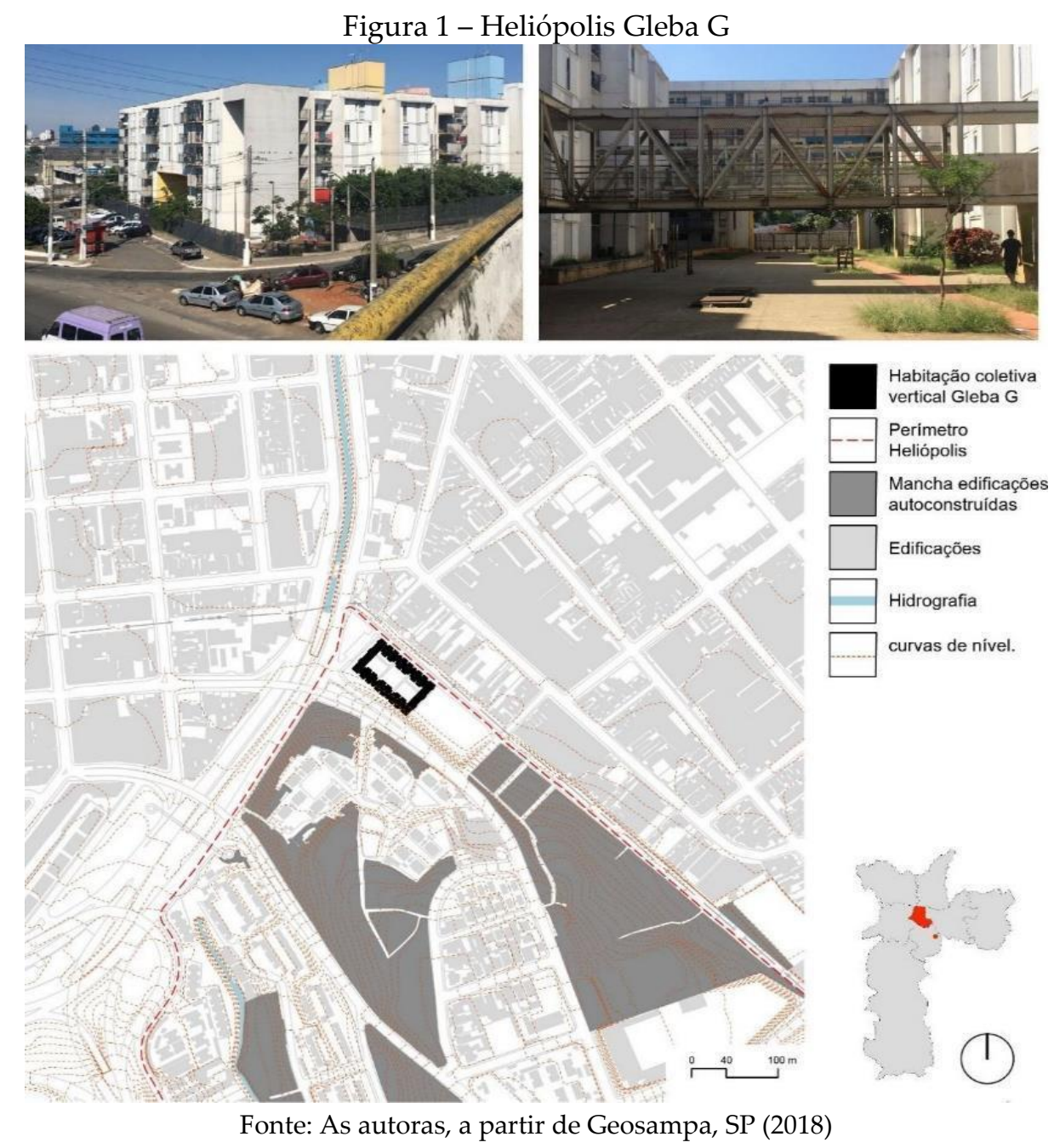


Dentre suas características morfológicas destaca-se o espaço livre do tipo pátio e o afastamento nulo da edificação em umas das ruas. Além do pátio central, as ruas contíguas ao lote e a praça integram os espaços livres de uso coletivo analisado (figura 2). Quanto às variáveis humanizadoras, o ambiente analisado é marcado positivamente pela boa relação entre a altura das edificações e a largura do pátio, circulações horizontais semiabertas, o caráter flexível do pátio, fachadas porosas voltadas tanto para rua quanto para o pátio.

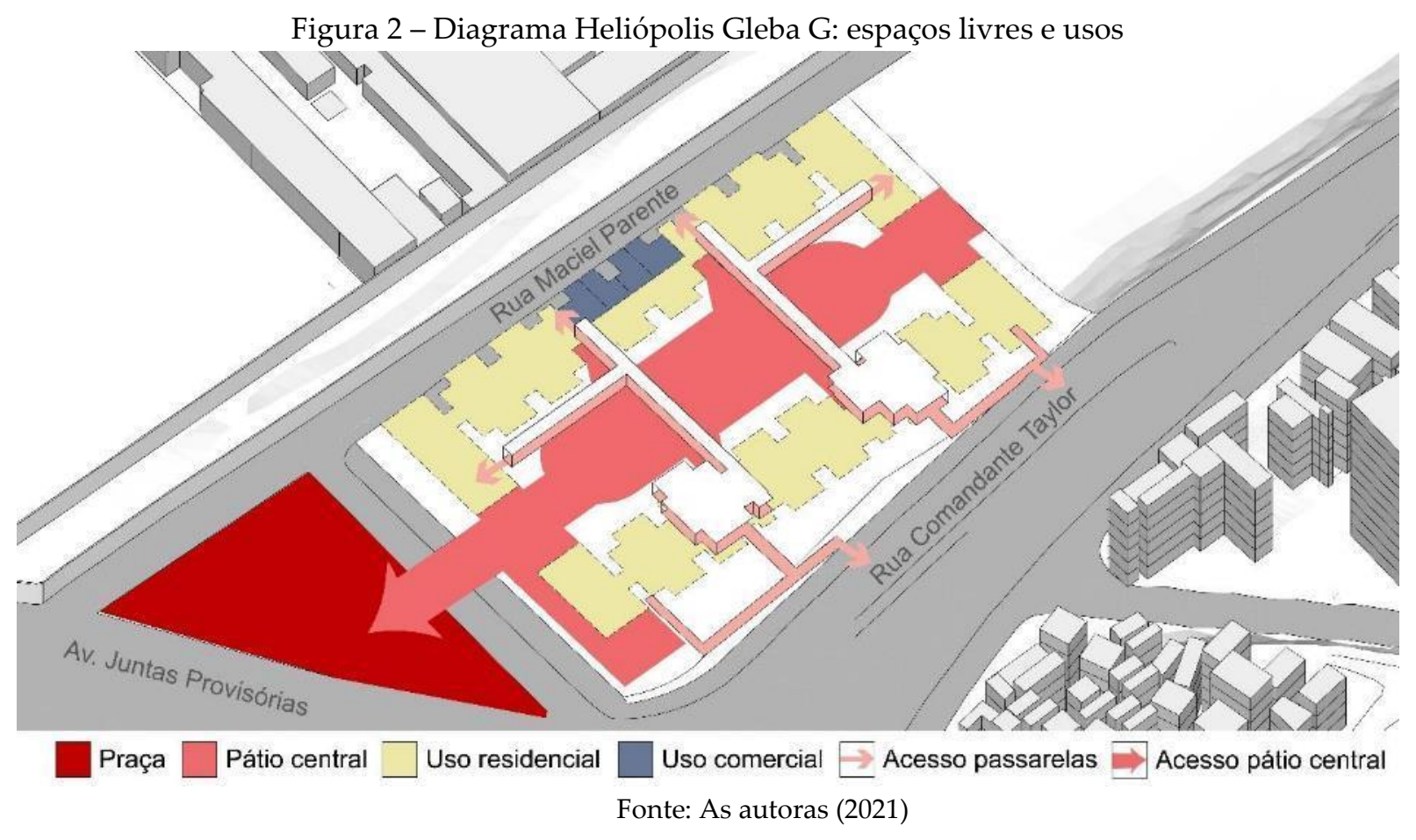

A praça e o pátio são os espaços livres utilizados com maior frequência para convívio coletivo e interação social, enquanto nas ruas adjacentes, as apropriações cotidianas estão associadas com os trajetos cotidianos ou com a guarda de veículos dos moradores.

Ao adentrar no conjunto, as passarelas e as circulações horizontais semiabertas voltadas para o pátio propiciam a interação entre aqueles que nelas circulam com as pessoas que estão no pátio (Figura 3A). O pátio central é utilizado por todas as faixas de idade e se configura como uma espacialidade social (Figura 3B). Seu caráter flexível permite a realização das reuniões de condomínio e a adaptação do espaço para diversas brincadeiras das crianças.

Quanto à praça externa, parte dela e o seu entorno são usados como estacionamento. Cotidianamente, ela é pouco usada para permanência. Por estar no meio do trajeto entre Heliópolis e a Estação Tamanduateí, o movimento é constante. Ao longo das visitas notou-se o seu potencial de atrair atividades comerciais, seja pela presença de trailers, seja pelas barracas improvisadas para a venda de espetinho. Ainda, de forma mais esporádica, feiras de empreendedorismo e eventos culturais e de conscientização são realizadas na praça, configurando uma espacialidade pública. As principais apropriações identificadas nessa unidade de caso foram sintetizadas na figura 4 . 
Figura 3 - Desenhos de observação do Heliópolis Gleba G

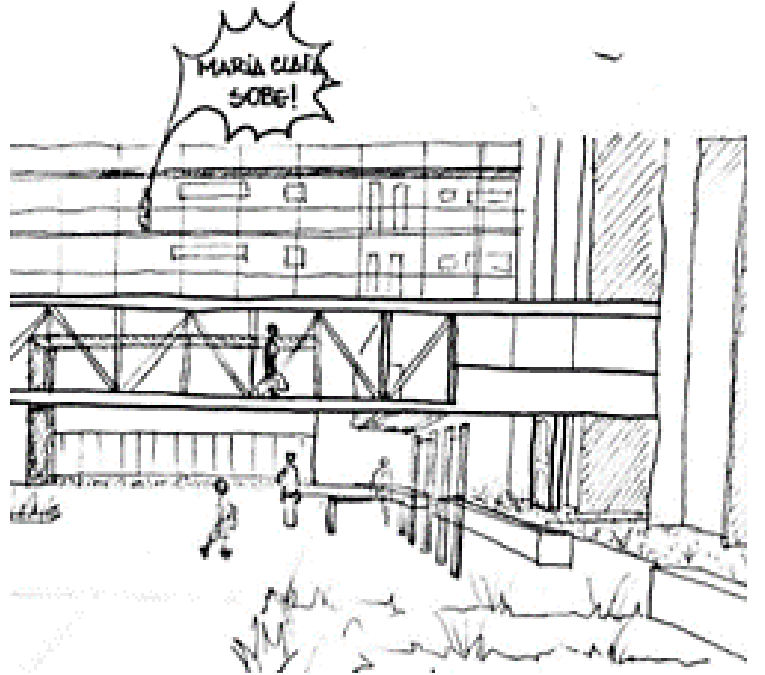

A

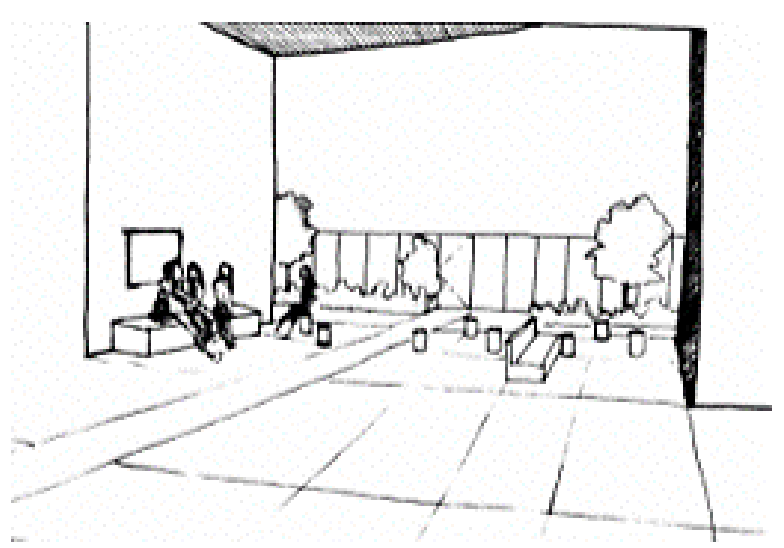

B

Fonte: As autoras (2021)

Figura 4 - Diagrama apropriações Heliópolis Gleba G

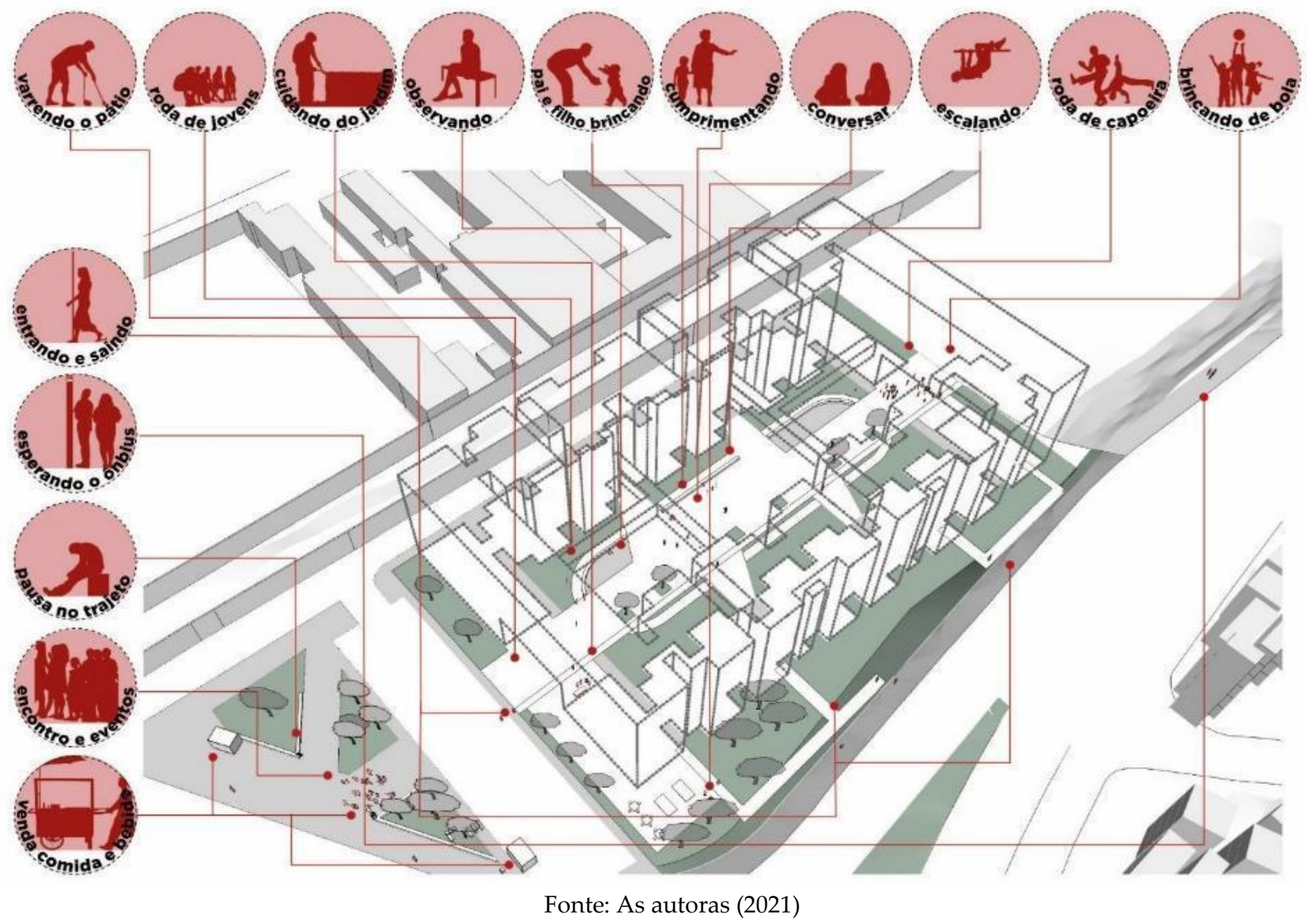




\subsection{Jardim Nazaré}

Favela localizada na Região do Itaim Paulista se estruturou ao longo de um corpo hídrico. Em 2004, foi realizado o projeto de intervenção urbana para melhorar as condições de saneamento, drenagem, moradia e integração da área com o entorno próximo (figura 5).

Figura 5 - Jardim Nazaré
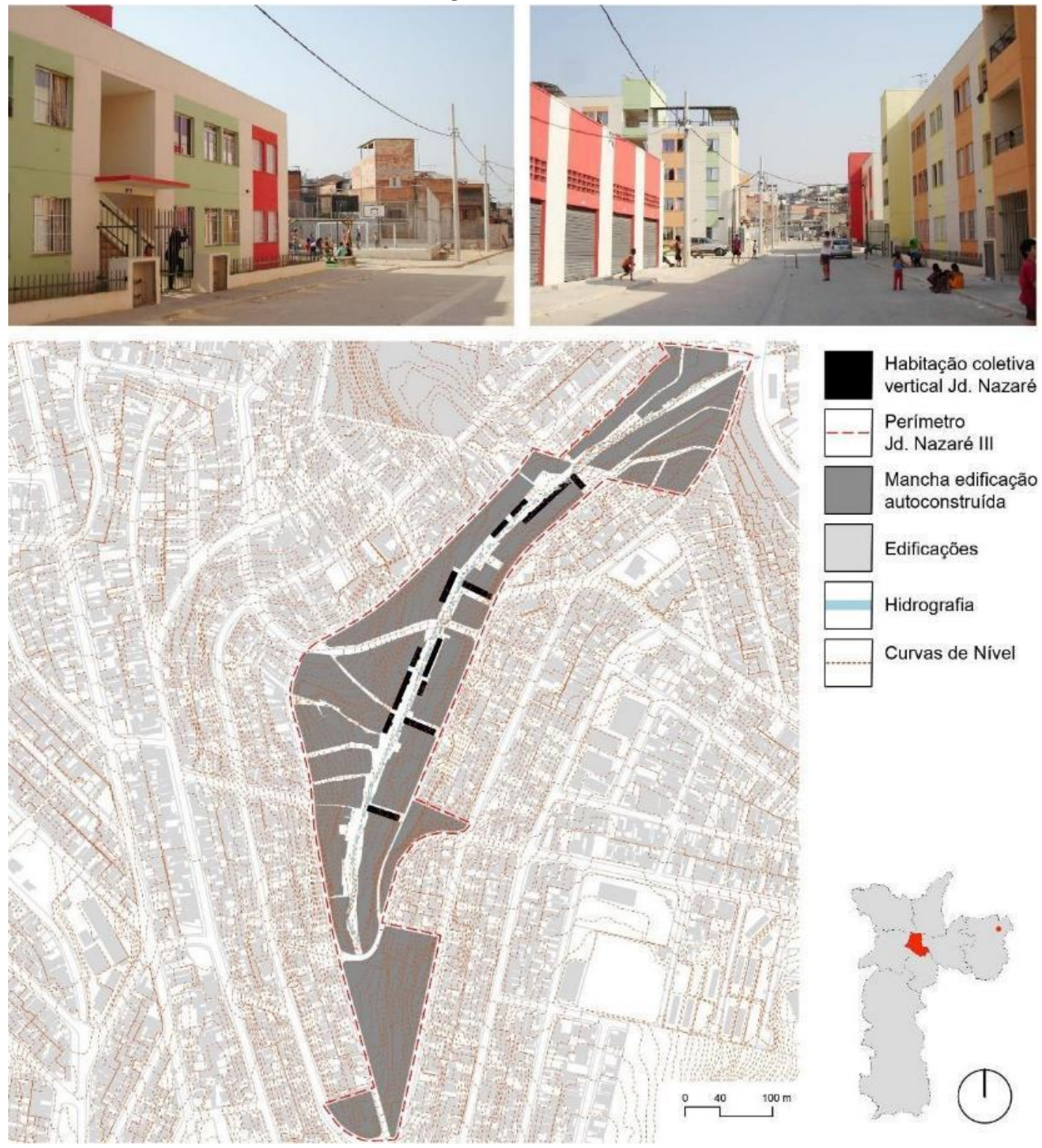

Fonte: As autoras, a partir de Geosampa, SP (2012) e Acervo Stetson Laureu

Antes da intervenção, o local possuía poucos pontos de conexão transversal. Com a intervenção, as vias destacadas na figura 6 (seta fina bordô) ou foram pavimentadas ou construídas, aumentando a permeabilidade da área e diminuindo o isolamento físico. Foram construídos quatro boxes comerciais, um centro comunitário e vinte novos edifícios habitacionais. Esses edifícios possuem recuo nulo nas laterais e se conjugam com as edificações existentes ou novas, conformando o traçado da rua, dotando-a de legibilidade. No afastamento existente entre os novos edifícios habitacionais e a rua, foram construídos 
pequenos jardins que fazem a transição entre o público e privado e garantem privacidade aos moradores do pavimento térreo. Além das características morfológicas descritas, a área é marcada pela diversidade de usos. Quanto às características humanizadoras, nota-se a flexibilidade de uso em alguns trechos da rua e alguns locais públicos marcados pela presença de arborização, garantindo aprazibilidade.

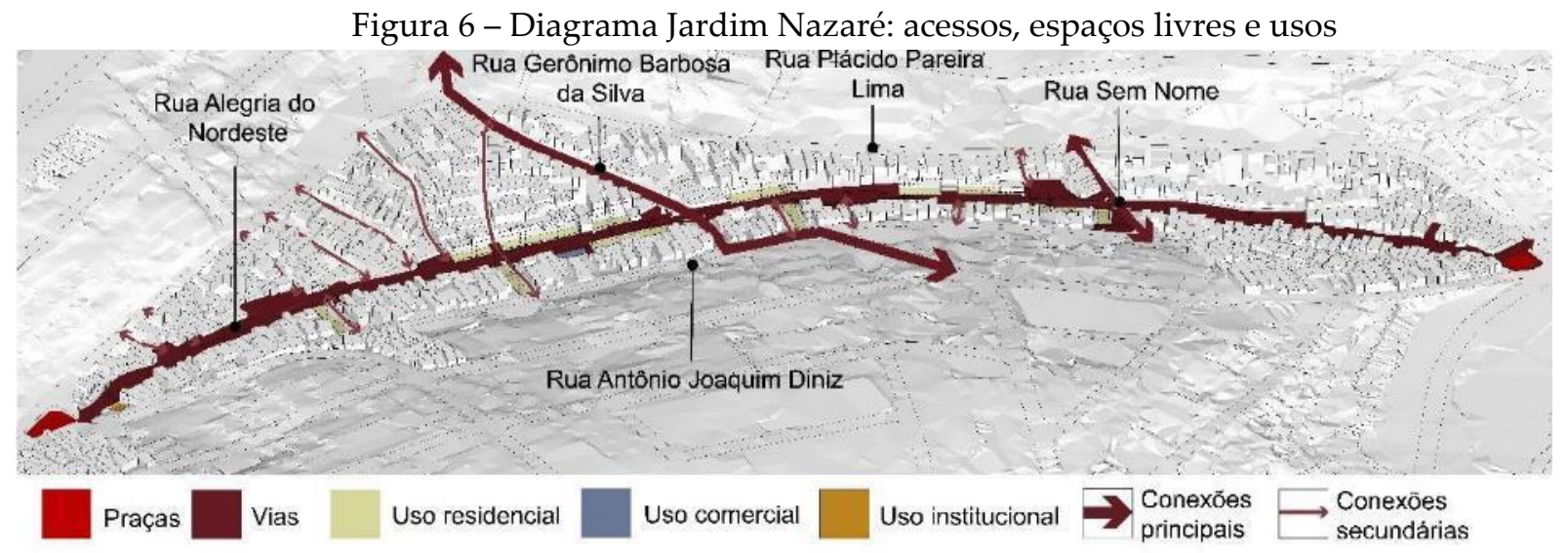

Fonte: As autoras

O córrego existente foi canalizado e sobre ele foi construída a Rua Alegria do Nordeste, infelizmente eliminando a presença do elemento natural na paisagem. A rua tornou-se pouco movimentada de carros, pois uma ponta é sem saída e na outra a curva fechada obriga a diminuição da velocidade dos veículos. Somado a esses fatores, o piso intertravado em toda a sua extensão também estimula a baixa velocidade e favorece o convívio e a permanência de pedestres. Ao longo desta mesma rua, pequenos bolsões de atividades ampliam a calçada para as pessoas. Em dois deles, existe uma pequena quadra esportiva. Nos outros, foram instalados brinquedos infantis de madeira, bancos e mesas. Nas extremidades da rua existem duas praças, integrando os espaços livres coletivos analisados.

Quanto às apropriações, o bolsão de atividade próximo ao centro comunitário, as duas quadras esportivas e um trecho da rua em frente aos boxes comerciais são os espaços livres mais utilizados para interação e convívio social (figura 8). A partir dos dados coletados, foram identificadas nesses lugares espacialidades privadas, públicas e sociais.

As quadras são especialmente usadas pelos jovens e crianças do sexo masculino. Mas também apresentam especificidades. Na quadra 1, próxima ao centro comunitário, as apropriações também estão ligadas à vida privada das casas vizinhas, porque, além de abrigar a brincadeira das crianças, alguns moradores aproveitam o alambrado para secar as roupas. Na quadra 2, os bancos atraem os jovens que aos finais de semana se agrupam para conversar e ouvir música (figura 7A).

Com o passar do tempo, alguns bolsões de atividade foram sendo alterados favorecendo a sua consolidação ou sua extinção. Alguns espaços que não receberam manutenção para a preservação dos bancos e dos brinquedos de madeiras foram substituídos por novas residências. Esse fato evidencia que existe um conflito entre a necessidade do espaço livre e a necessidade de moradia.

Ao mesmo tempo, além da preservação das quadras esportivas, foi observado a permanência de outros espaços livres propostos pela intervenção. Como por exemplo, o bolsão na esquina da Rua Gerônimo 
Barbosa onde foi possível identificar algumas transformações, como bancos de madeiras feitos pelos moradores e tubos de PVC para proteger o local (figura 7B).

Figura 7 - Desenhos de observação do Jardim Nazaré

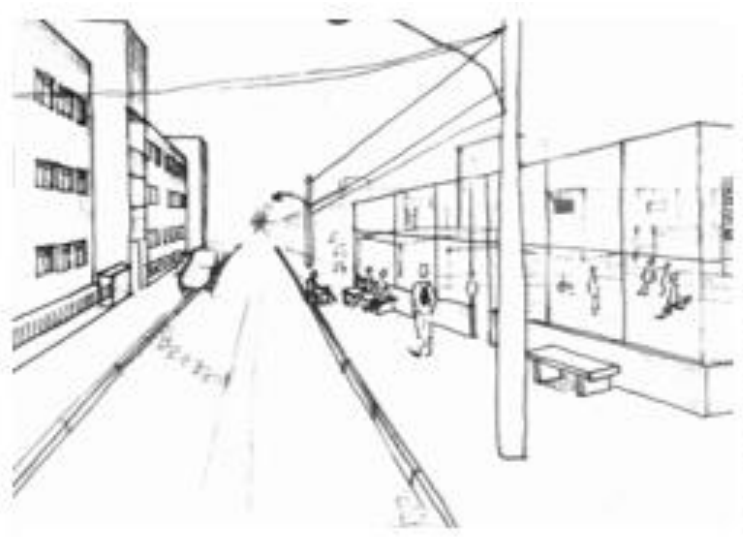

A

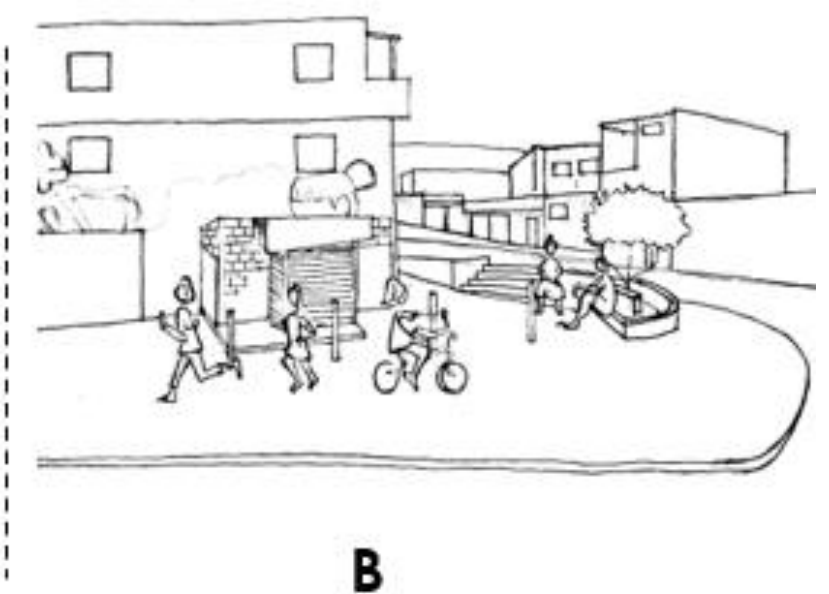

Fonte: As autoras

Também foi identificada a apropriação da rua pelos donos dos estabelecimentos comerciais, usufruindo e adequando a calçada com mesas e coberturas para atrair clientes. Nos boxes comerciais construídos pela intervenção, notou-se a autoconstrução de um segundo pavimento destinado à habitação.

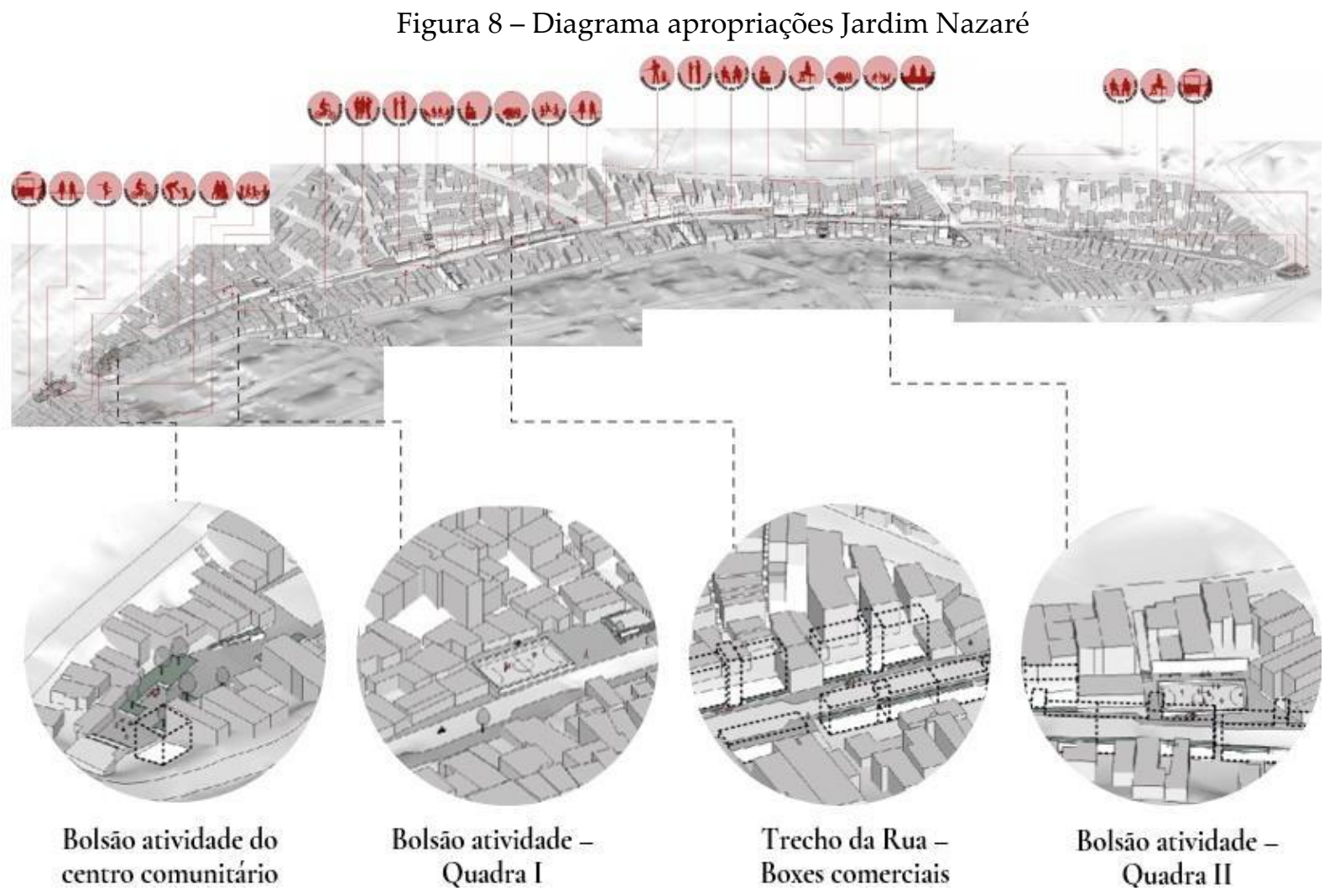

Fonte: As autoras 
Outro bolsão com maior frequência de uso está localizado em frente ao centro comunitário. Pais e avós levam seus filhos e netos para brincar nesse espaço livre e a instituição responsável pela administração do centro, utiliza o espaço para desenvolver diversas atividades com as crianças que participam de seus projetos sociais.

Por fim, entre os espaços livres ofertados, a praça em frente ao centro comunitário, também é apropriada para interação e uso social, onde os moradores aproveitam de sua sombra. Na praça também existe a presença de um trailer de lanches. Mesas e cadeiras indicam que em algum momento do dia elas são dispostas para o uso da clientela. As principais apropriações identificadas nessa unidade de caso foram sintetizadas na figura 8 .

\section{APROPRIAÇÕES E ESPACIALIDADES}

A partir das características morfológicas, das apropriações e das espacialidades coletadas nas unidades caso, pistas foram encontradas com a finalidade de dar suporte ao trabalho de arquitetos e urbanistas em intervenções futuras. Essas pistas projetuais, devem ser entendidas como uma recomendação para incentivar práticas de acolhimento, podendo ser vinculadas a outras espacialidades e programas.

Os resultados principais foram organizados no quadro 2. Para cada recomendação proposta tem um croqui e uma foto correspondentes que resgatam onde a pista foi identificada no estudo de caso. 
Quadro 2 - Pistas encontradas

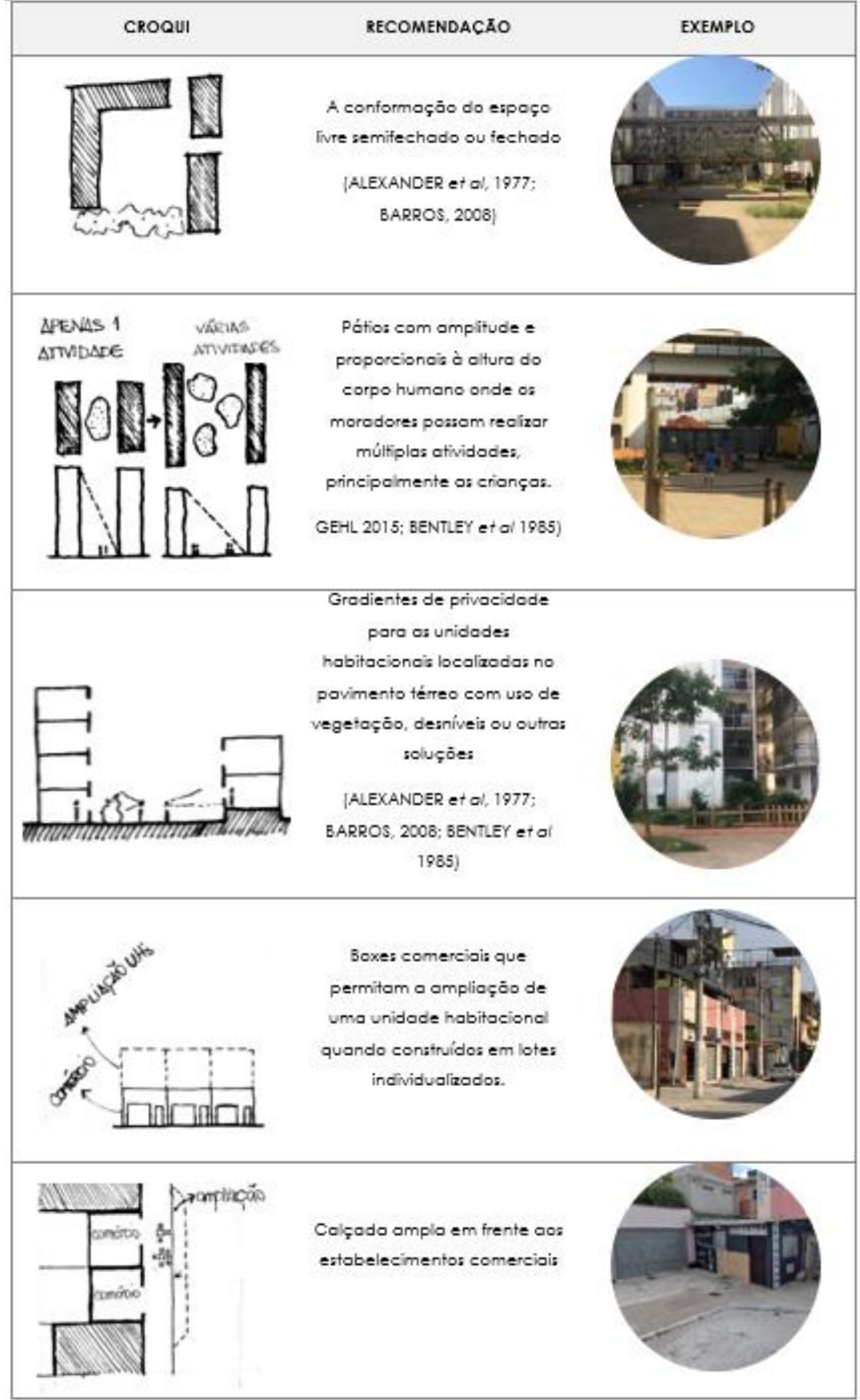




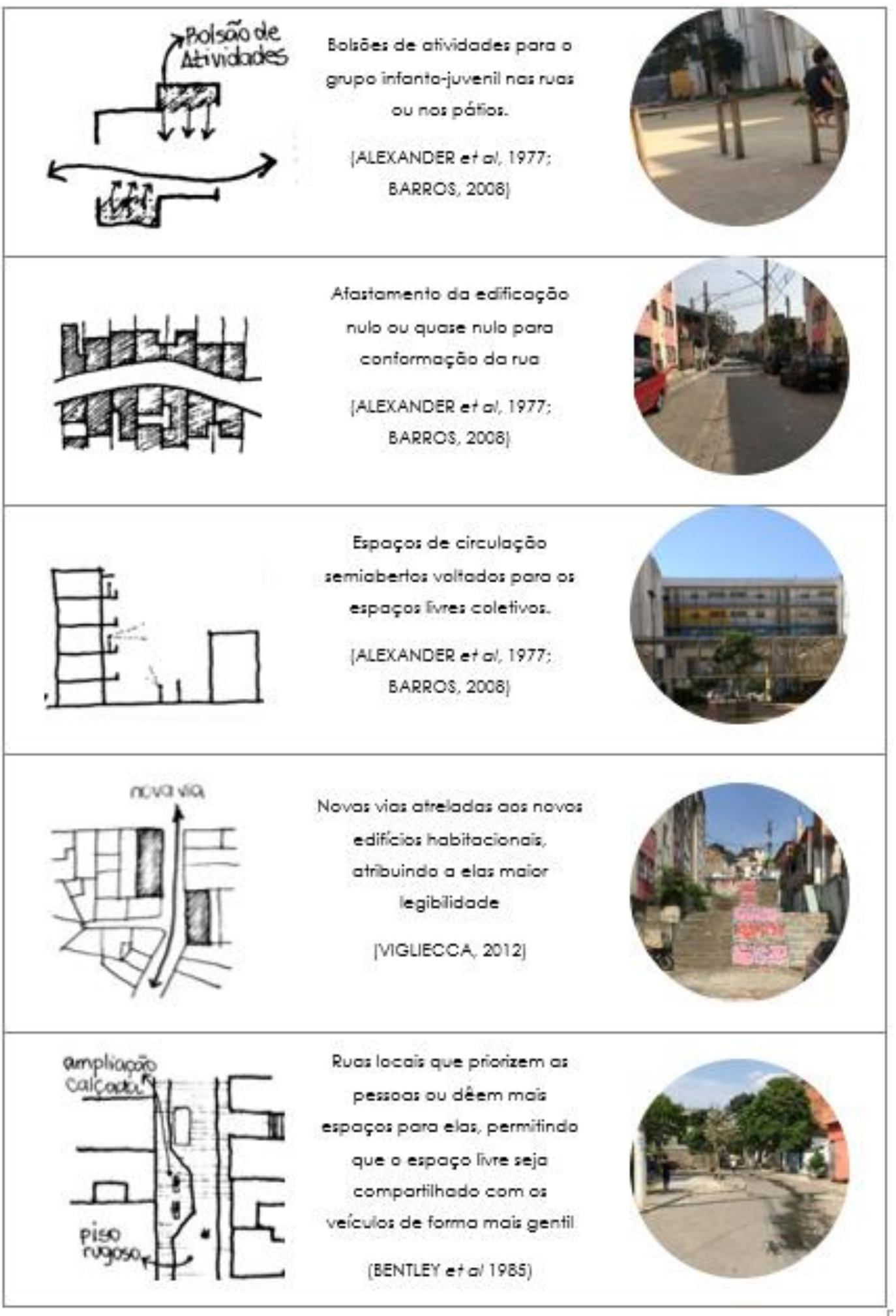

Fonte: As autoras 


\section{CONCLUSÕES}

Dentre as contribuições dessa pesquisa, é importante salientar que as variáveis foram utilizadas como instrumento de análise de espaços existentes, mas seu uso pode ser expandido e aprofundado em novos estudos de caso e aplicado como parâmetros projetuais em novas intervenções de habitação social.

Os fatores qualitativos e suas variáveis de análise foram úteis no estudo de caso para se ter uma visão ampla de como as dimensões morfológicas e humanizadoras do espaço se refletem na apropriação. Em ambas as unidades do estudo, a concepção arquitetônica e urbanística apoiou positivamente a configuração dos espaços livres coletivos, sendo identificados os principais conceitos humanizadores no desenho desses lugares.

O método proposto para análise das apropriações dos espaços livres atreladas com as características morfológicas e humanizadoras apontou tendências de qualidades espaciais que intensificam as apropriações.

\section{AGRADECIMENTOS}

Aos moradores e trabalhadores do Jardim Nazaré e Heliópolis Gleba G pela receptividade e por permitirem conhecer o seu cotidiano, fundamental para o objetivo dessa pesquisa. À Equipe de Divisão ao Trabalho Social (DTS/Sudeste) da Prefeitura de São Paulo, ao Conselho Comunitário de Segurança (CONSEG), à equipe do Brincar Prosear E Filosofar o Eca, À Fabio Pereiro dos Santos e à Stetson Lareu por compartilharem, cada em sua especificidade, a experiência de trabalho realizada nas áreas analisadas.

\section{REFERÊNCIAS}

ALEXANDER, C.; ISHIKAWA, S.; SILVERSTEIN, M.; JACOBSON, M.; FIKSDAHL-KING, I.; ANGEL, S. A pattern language: towns, buildings, construction. New York: Oxford Univ., 1977.

BARROS, R. R. M. P. Habitação coletiva: a inclusão de conceitos humanizadores no processo de projeto. 2008. Tese (doutorado em Arquitetura, Tecnologia e Cidade) - Faculdade de Engenharia Civil e Arquitetura, Universidade Estadual de Campinas, Campinas, 2008.

BENTLEY, I., ALCOCK, A., MURRAIN, P., MCGLYNN, S., SMITH, G. Responsive environments: A manual for designers. Oxford: Architectural Press, 1985.

BERGHAUSER PONT, M. Y.; HAUPT, P. A. Space, density and urban form. Netherlands: 2009.

BRANDÃO, P. (coord.). O chão da cidade: guia de avaliação do design de espaço público. Lisboa: Centro português de Design, 2002.

GARCÍA-PÉREZ, S.; OLIVEIRA, V; JAVIER, M; MEDINA, C. D. UR-Hesp: A methodological approach for a diagnosis on the quality of open spaces in mass housing estates. Cities, v.103, p. 1-17, dez. 2020. Disponível em: https://doi.org/10.1016/j.cities.2020.102657. Acesso em: 9 jul. 2020.

GEHL, J. Cidades para pessoas. São Paulo: Perspectiva, 2015. 
PELLI, V. S. Habitar, participar, pertenecer: acceder a la vivienda incluirse en la sociedad. Buenos Aires: Nobuko, 2007.

PROCOPIO, C.; PINA. S. Transformações nos espaços livres na urbanização de áreas habitacionais em São Paulo. In: Anais 8ª Conferência da Rede Lusófona de Morfologia Urbana PNUM. Maringá: UEM, p.13941382, 2019.

QUEIROGA, E. F. Espacialidades da Esfera Pública na Urbanização Contemporânea: O Caso da Megalópole do Sudeste. In: KAHTOUNI, S; MAGNOLI, M. M; TOMINANGA, Y. (org.) Discutindo a paisagem. São Carlos: Rima, 2006.

SANTOS, C. N.; VOGEL, A. (org.). Quando a rua vira casa. Rio de Janeiro: Ibam/Finep, 1985.

SANTOS, M. A natureza do Espaço. São Paulo: Edusp, 1996.

TELLES, V. S. Espaço público e espaço privado na constituição do social: notas sobre o pensamento de Hannah Arendt. Tempo Social, São Paulo, v.2, n.1, p.23-48,1990. 